\title{
MUSCLE REGENERATION POTENTIAL AND SATELLITE CELL ACTIVATION PROFILE DURING RECOVERY FOLLOWING HINDLIMB IMMOBILIZATION IN MICE
}

\begin{tabular}{|r|l|}
\hline Journal: & Journal of Cellular Physiology \\
\hline Manuscript ID & JCP-17-0286.R1 \\
\hline Wiley - Manuscript type: & Original Research Article \\
\hline Date Submitted by the Author: & n/a \\
\hline Complete List of Authors: & $\begin{array}{l}\text { Guitart, Maria; IMIM-Hospital del Mar, Parc de Salut Mar, CIBER } \\
\text { Lloreta, Josep; Hospital del Mar, Parc de Salut Mar, Health and } \\
\text { Experimental Sciences Department (CEXS), Universitat Pompeu Fabra } \\
\text { (UPF), Barcelona Biomedical Research Park (PRBB), Pathology Department } \\
\text { Manas-Garcia, Laura; IMIM-Hospital del Mar, Parc de Salut Mar, UPF, PRBB } \\
\text { Barreiro, Esther; IMIM-Hospital del Mar, UPF, PRBB, CIBERES, } \\
\text { Pulmonology-URMAR }\end{array}$ \\
\hline Key Words: & $\begin{array}{l}\text { hindlimb immobilization, hindlimb recovery, muscle regeneration markers, } \\
\text { muscle progenitor cells and satellite cell counts, electron microscopy }\end{array}$ \\
\hline
\end{tabular}

SCHOLARONE ${ }^{m}$

Manuscripts 
1 MUSCLE REGENERATION POTENTIAL AND SATELLITE CELL

\section{ACTIVATION PROFILE DURING RECOVERY FOLLOWING HINDLIMB}

3 IMMOBILIZATION IN MICE

4 Maria Guitart ${ }^{1,2}$, Josep Lloreta ${ }^{3}$, Laura Mañas-Garcia ${ }^{1}$, Esther Barreiro ${ }^{1,2}$

$5{ }^{1}$ Pulmonology Department-Muscle Wasting and Cachexia in Chronic Respiratory

6 Diseases and Lung Cancer Research Group, IMIM-Hospital del Mar, Parc de Salut

7 Mar, Health and Experimental Sciences Department (CEXS), Universitat Pompeu

8 Fabra (UPF), Barcelona Biomedical Research Park (PRBB), Barcelona.

$9 \quad{ }^{2}$ Centro de Investigación en Red de Enfermedades Respiratorias (CIBERES), Instituto

10 de Salud Carlos III (ISCIII), Barcelona.

$11{ }^{3}$ Department of Pathology, Hospital del Mar, Parc de Salut Mar, Health and

12 Experimental Sciences Department (CEXS), Universitat Pompeu Fabra (UPF),

13 Barcelona Biomedical Research Park (PRBB), Barcelona.

14 Corresponding author: Dr. Esther Barreiro, Pulmonology Department, IMIM-

15 Hospital del Mar, PRBB, Dr. Aiguader, 88, E-08003 Barcelona, Spain, Telephone: +34

1693316 0385, Fax: +3493 3160410 , e-mail: ebarreiro@imim.es

17 Word count: $\mathbf{5 , 2 7 4}$

18 Running head: Muscle progenitors in disuse and recovery

19 KEY WORDS:

20 - hindlimb immobilization

21 - hindlimb recovery

22 - muscle progenitor cells and satellite cell counts

23 - electron microscopy

24 - muscle regeneration markers

25 Number of text figures: 7

John Wiley \& Sons, Inc. 


\section{Number of tables: 2}

\section{Grant information:}

28 Contract grant sponsor: Instituto de Salud Carlos-III, contract grant numbers, 29 CIBERES, FIS 14/00713 (FEDER).

30 Contract grant sponsor: Spanish Respiratory Society (SEPAR), contract grant numbers,

31 SEPAR 2013 and 2016

32 Contract grant sponsor: Catalan Foundation of Pulmonology (FUCAP), contract grant 33 numbers, FUCAP 2016. 
1

2

3

4

5

6

7

8

9

10

11

12

13

14

15

16

17

18

19

20

21

22

23

24

25

26

27

28

29

30

31

32

33

34

35

36

37

38

39

40

41

42

43

44

45

46

47

48

49

50

51

52

53

54

55

56

57

58

59

60

\section{ABSTRACT}

36 Reduced muscle activity leads to muscle atrophy and function loss in patients and

37 animal models. Satellite cells (SCs) are postnatal muscle stem cells that play a pivotal

38 role in skeletal muscle regeneration following injury. The regenerative potential,

39 satellite cell numbers, and markers during recovery following immobilization of the

40 hindlimb for seven days were explored. In mice exposed to seven days of hindlimb

41 immobilization, in those exposed to recovery (seven days, splint removal), and in

42 contralateral control muscles, muscle precursor cells were isolated from all hindlimb

43 muscles (fluorescence-activated cell sorting, FACS), and SCs and muscle regeneration

44 were identified using immunofluorescence (gastrocnemius and soleus) and electron

45 microscopy (EM, gastrocnemius). Expression of ki67, pax7, myoD, and myogenin was

46 quantified (RT-PCR) from SC FACS yields. Body and grip strength were determined.

47 Following seven-day hindlimb immobilization, a decline in SCs (FACS,

48 immunofluorescence) was observed together with an upregulation of SC activation

49 markers and signs of muscle regeneration including fusion to existing myofibers (EM).

50 Recovery following hindlimb immobilization was characterized by a program of muscle

51 regeneration events. Hindlimb immobilization induced a decline in SCs together with an

52 upregulation of markers of SC activation, suggesting that fusion to existing myofibers

53 takes place during unloading. Muscle recovery induced a significant rise in muscle

54 precursor cells and regeneration events along with reduced SC activation expression

55 markers and a concomitant rise in terminal muscle differentiation expression. These are

56 novel findings of potential applicability for the treatment of disuse muscle atrophy,

57 which is commonly associated with severe chronic and acute conditions.

58 Word count: 250

59

John Wiley \& Sons, Inc. 


\section{INTRODUCTION}

61 Skeletal muscle dysfunction and mass loss are characteristic features in patients with

62 chronic diseases including cancer of several types and acute conditions such as critical 63 illness. Impaired muscle function and atrophy limit the patients' quality of life as 64 exercise tolerance and daily life activities can be seriously hampered especially 65 following prolonged intensive care unit (ICU) stay. Furthermore, skeletal muscle 66 dysfunction and atrophy have also been shown to predict morbidity and mortality in 67 patients regardless of the underlying condition (Barreiro et al, 2015a;Fearon et al, 68 2011; Maltais et al, 2014;Marquis et al, 2002; Seymour et al, 2010; Vogelmeier et al, 69 2017;Barreiro et al, 2015b;Patel et al, 2014;Swallow et al, 2007). Several factors and 70 biological mechanisms have been demonstrated to be involved in the pathophysiology 71 of skeletal muscle mass loss (Barreiro and Sznajder, 2013;Barreiro et al, 2015a;Barreiro 72 and Gea, 2015;Barreiro and Gea, 2016;Barreiro, 2017;Maltais et al, 2014). 73 Deconditioning and reduced muscle activity are counted among the most relevant 74 factors leading to muscle atrophy and loss of function in patients (Barreiro and Gea, 75 2015;Barreiro et al, 2015a;Fearon et al, 2011;Maltais et al, 2014;Marquis et al, 76 2002; Seymour et al, 2010) and animal models (Chacon-Cabrera et al, 2016;Chacon77 Cabrera et al, 2017a).

Biological mechanisms such as increased oxidative stress, mitochondrial 79 alterations, enhanced protein breakdown, epigenetic events, and signaling pathways 80 mediate muscle mass loss in experimental models of cancer-induced cachexia, chronic 81 heart failure, and disuse muscle atrophy and in cachectic patients with chronic 82 respiratory conditions (Barreiro et al, 2016; Chacon-Cabrera et al, 2014; Chacon-Cabrera 83 et al, 2015; Chacon-Cabrera et al, 2016; Chacon-Cabrera et al, 2017b; Chacon-Cabrera et 84 al, 2017a;Fermoselle et al, 2012;Puig-Vilanova et al, 2014b;Puig-Vilanova et al, 
85 2014a;Puig-Vilanova et al, 2015;Barreiro and Sznajder, 2013;Barreiro and Gea, 86 2015;Barreiro and Gea, 2016). Recently, we have demonstrated that a specific program 87 of molecular and cellular events characterized by increased muscle proteolysis and 88 injury was observed in the gastrocnemius of mice following hindlimb unloading for 89 several time-points, while reloading of the muscle improved all those alterations 90 (Chacon-Cabrera et al, 2016). Additionally, in the same mouse model, muscle-enriched 91 microRNAs, especially miR-486, through paired box (pax)7 regulation was shown to 92 delay muscle cell differentiation, probably via acetylation of fork-head box (FoxO)1 and 933 , in the unloaded gastrocnemius (Chacon-Cabrera et al, 2017a). Interestingly, reloading 94 of the muscle after splint removal induced a rise of the histone deacetylase sirtuin-1 95 along with a decrease in acetylation levels of the transcription factors FoxO1 and 3, thus 96 enabling the muscle fibers to regenerate in the mice (Chacon-Cabrera et al, 2017a). We 97 concluded that the kinetics of the biological events leading to skeletal muscle mass loss 98 and recovery were tightly regulated in the gastrocnemius of mice exposed to different 99 time-points of muscle unloading and reloading (Chacon-Cabrera et al, 2016; Chacon100 Cabrera et al, 2017a). Whether the potential of muscle regeneration was altered in 101 response to disuse remained unexplored in the former investigations.

102 Satellite cells are postnatal muscle stem cells that play a pivotal role in the 103 regeneration of skeletal muscle following injury. Satellite cell populations are 104 heterogeneous and may differ in features such as their myogenic differentiation 105 predisposition, gene expression profile, lineage potential of nonmyogenic fates, and 106 stemness. Interestingly, different studies have also demonstrated modifications in 107 satellite cell numbers in response to different stimuli and models of disuse muscle 108 atrophy (Arentson-Lantz et al, 2016;Snijders et al, 2014; Suetta et al, 2013). On this 109 basis, we focused the current investigation on the assessment of the regenerative 
110 potential and satellite cell numbers during recovery following immobilization of the

111 hindlimb for seven days. This experimental approach enabled us to mimic a

112 physiological condition (immobilization) compared to other models in which myotoxins

113 have been used to trigger muscle regeneration following injury in mice. The seven-day

114 time-point was chosen on the basis of previous studies (Chacon-Cabrera et al,

115 2016; Chacon-Cabrera et al, 2017a), in which early and late biological regeneration

116 events could be identified. Furthermore, we also hypothesized that a differential pattern

117 of myogenic precursor cell markers may be expressed in the satellite cells of the

118 hindlimb muscles exposed to unloading and reloading, respectively. Accordingly, we

119 sought to specifically investigate in the hindlimb muscles of mice exposed to seven-day

120 periods of unloading and reloading: 1) muscle progenitor cell counts isolated from all

121 the hindlimb muscles using fluorescent-activated cell sorting (FACS), 2) levels of

122 satellite cells and regeneration events using histological (immunofluorescence,

123 gastrocnemius and soleus) and electron microscopy analyses (gastrocnemius), and 3) to

124 analyze the specific pattern of myogenic precursor cell markers in the satellite cell

125 yields obtained from the FACS analyses. The model of disuse-induced muscle atrophy

126 and recovery employed in the current investigation has been previously well-validated

127 (Chacon-Cabrera et al, 2016; Chacon-Cabrera et al, 2017a).

129 MATERIALS AND METHODS

130 Animal experiments and Ethics approval

131 Female C57BL/6J mice (10 weeks old, weight $\sim 20 \mathrm{~g}$ ) were obtained from Harlan

132 Interfauna Ibérica SL (Barcelona, Spain). Mice were kept under pathogen-free

133 conditions in the animal house facility at Barcelona Biomedical Research Park (PRBB),

134 with a 12:12 hour light: dark cycle.

135 Mice were exposed to unilateral hindlimb immobilization as previously 
136 described to reproduce a model of disuse muscle atrophy (Chacon-Cabrera et al,

137 2016; Chacon-Cabrera et al, 2017a). Briefly, the left hindlimb was shaved with clippers

138 and was enveloped using surgical tape. The hindlimb was introduced in a $1.5 \mathrm{~mL}$

139 microcentrifuge tube with cover and bottom lids removed, while maintaining the foot in

140 a plantar-flexed position to induce the maximal atrophy of the target limb muscles:

141 gastrocnemius, soleus, tibialis anterior (TA), extensor digitorum longus (EDL) and

142 quadriceps femoris $(\mathrm{QF})$. The entire procedure was carried out using mouse restrainers,

143 without anesthesia. As the weight of the tube was approximately $0.6 \mathrm{~g}$, it did not

144 interfere with the usual mobility of the mice. In this study, for satellite cell isolation

145 experiments a total number of 40 mice were employed. Animals were further

146 subdivided into the two following groups: 1) 7-day immobilization group (7-day I,

$147 \mathrm{~N}=20$ /group) and 2) 7-day recovery group (7-day $\mathrm{R}, \mathrm{N}=20$ /group), in which the splint

148 was removed following the seven-day immobilization period to let the animals move

149 freely in their cages in order to evaluate muscle recovery. The target samples were

150 obtained by pooling together the gastrocnemius, soleus, TA, EDL and QF muscles from

151 two different mice belonging to the same study group. The gastrocnemius, soleus, TA,

152 EDL and QF from two different mice belonging to the contralateral hindlimb from the

153 7-day $\mathrm{I}$ or 7-day $\mathrm{R}$ groups of mice served as the control muscles. For the

154 immunofluorescence and electron microscopy experiments a total number of 16

155 additional mice were employed (see below specific details for this type of experiments).

156 The animals were also divided into two groups (7-day I and 7-day R mice, n=8/group).

157 The gastrocnemius muscle was cut into two fragments that were used for

158 immunofluorescence and electron microscopy analyses, respectively. Given the very

159 small size of the soleus, only histological (immunofluorescence) analyses could be

160 conducted on this muscle.

John Wiley \& Sons, Inc. 
161 All animal experiments were conducted in the animal facilities at Parc de

162 Recerca Biomèdica de Barcelona (PRBB). This controlled study was designed in 163 accordance with the European Community Directive 2010/63/EU and Spanish

164 Legislation (Real Decreto 53/2013, BOE 34/11370-11421, 2013) for the use and care of 165 animals followed in our institution (PRBB animal facilities) and the Helsinki 166 convention for the use and care of animals. Ethical approval was obtained by the 167 Animal Research Committee (Animal welfare department in Catalonia, Spain, EBP-13168 1485).

169 In vivo measurements in the mice

170 In all the study animals, food intake was measured daily, and food and water were 171 supplied ad libitum for the entire duration of the immobilization or recovery periods. In 172 all mice, body weight and limb strength were determined on day 0 , and right at the end 173 of the immobilization or recovery time-points (day 7, as described above) using a scale 174 and a grip strength meter (Bioseb, Vitrolles, France), respectively, as previously 175 reported (Barreiro et al, 2016; Chacon-Cabrera et al, 2014; Chacon-Cabrera et al, 176 2015; Chacon-Cabrera et al, 2016; Chacon-Cabrera et al, 2017b;Chacon-Cabrera et al, 177 2017a). In the two groups of animals, total body weight and limb strength gain variables 178 were calculated as the percentage of the measurements performed at the end of the study 179 period (7-day I or 7-day R) with respect to the same measurements obtained at baseline 180 (day 0 or on day 7 following the immobilization protocol) in the 7-day I and 7-day $\mathrm{R}$ 181 study groups, respectively.

\section{Sacrifice and sample collection}

183 Mice from all experimental groups were sacrificed after the corresponding 184 immobilization or recovery time-cohort. Each mouse was previously inoculated 185 intraperitoneally with $0.1 \mathrm{~mL}$ sodium pentobarbital $(60 \mathrm{mg} / \mathrm{Kg})$. In all cases, the pedal 
186 and blink reflexes were evaluated in order to verify total anesthetic depth. Animal

187 sacrifice took place following diaphragm extraction. For isolation of muscle cell

188 progenitor experiments the following muscles were obtained from all the animals at the

189 time of sacrifice: gastrocnemius, soleus, TA, EDL and QF (entire muscles in all cases).

190 As abovementioned, all study muscles from the hindlimb were pooled together by

191 groups of two for each experimental condition (7-day I and 7-day R) as well as from the

192 contralateral control hindlimb muscles, thus a total of 10 samples were analyzed in each

193 group (contralateral control muscles and both 7-day I and 7-day R mice). For

194 immunofluorescence and electron microscopy experiments, gastrocnemius and soleus

195 muscles were obtained at the time of sacrifice in each experimental cohort. As soleus

196 muscle was very small, only immunofluorescence analyses, but not electron

197 microscopy, were conducted (see below specific details). For stem cell progenitor

198 isolation experiments, the muscle samples were preserved in cold Dubelcco's Modified

199 Eagle's Medium (DMEM) to be immediately processed as described below. For

200 identification of several muscle regeneration markers, RNA was extracted from the

201 isolated satellite cell yields (see below).

202 Satellite cell isolation using FACS

203 A schematic representation of these methodologies is shown in Figure 1. Immediately

204 after dissection, muscles were processed following a modified version of a previously

205 described protocol (Pasut et al, 2012) (Figure 1). Pools of gastrocnemius, soleus, TA,

206 EDL and QF muscles were first minced with scissors and secondly with a razor blade

207 (Electron microscopy science, Hatfield, PA, USA). The minced muscles were collected

208 in a 50-mL tube containing $40 \mathrm{~mL}$ of cold DMEM to be subsequently washed to remove

209 fat tissue. Enzymatic digestion with a DMEM media containing $2.5 \mathrm{U} / \mathrm{mL}$ collagenase

210 (Serva Electrophoresis, Heidelberg, Germany) and $2.5 \mathrm{U} / \mathrm{mL}$ dispase (Sigma Aldrich, 
211 Sant Louis, Missouri, USA) was immediately performed at $37^{\circ} \mathrm{C}$ in an agitation bath for 21210 minutes.

213 The digestion procedure was repeated four times and the digested muscle 214 solution was then filtered through a $100-\mu \mathrm{m}$ mesh filter (Corning, New York, NY, 215 USA). Immediately afterwards, the digestion was stopped by adding 2 volumes of $10 \%$ 216 fetal bovine serum (FBS) in phosphate buffered saline (PBS), and the muscle solution 217 was filtered through a $70-\mu \mathrm{m}$ mesh filter (Corning). The filtered solution was 218 centrifuged at $300 \times g$ for 5 minutes. The pellet was kept and the supernatant was 219 centrifuged again in order to recover the maximum amount of cells. Finally, the two cell 220 pellets were combined in a fresh tube to be re-suspended in FACS buffer [(1 mL PBS 221 solution containing 2.5\% goat serum (Sigma Aldrich)]. The number of cells was 222 counted using a Neubauer chamber.

223 Prior to incubations with antibodies, the cells were washed in $20-\mathrm{mL}$ cold 224 DMEM and centrifuged at 1,700 rpm for 10 minutes to recover the cell pellet. Cells 225 were resuspended in $1 \times 10^{6}$ cell/100 $\mu$ L FACS buffer. All these cells were incubated 226 with antibodies used to specifically identify the satellite cells: Phycoerythrin (PE)227 conjugated anti-alpha-7 integrin (Ablab, Vancouver, Canada), a heterodimeric integral 228 membrane protein critical for the modulation of cell-matrix interactions, and 229 allophycocyanin (APC)-conjugated anti-CD34 (BD Pharmigen, San Jose, CA, USA), as 230 a cell surface sialomucin (a mucopolysaccharide molecule containing sialic acid) with 231 reported anti-adhesive, motile, and pre-proliferative properties for 30 minutes.

232 Additionally, the cells from both study groups of mice were incubated at the same time 233 (30 minutes) with specific antibodies to exclude other cell type populations that might 234 have also been present in the muscle extracts, namely endothelial cells, leukocytes and 235 hematopoietic cells: phycoerythrin (PE)-cyanine7 (Cy7)-conjugated anti-CD31 
236 (Biolegend, San Diego, CA, USA), a marker of endothelial cells, both anti-CD11b

237 (Biolegend) and anti-CD45 (Biolegend) as markers of leukocytes, and anti-Sca-1

238 (Biolegend), a marker of hematopoietic stem cells. The excluded cell populations were 239 named negative-lineage [Lin $(-)]$.

240 Subsequently afterwards, all the study cells were incubated with 4',6-diamino-2-

241 fenilindol (DAPI) in order to exclude the dead cells (cells DAPI+ exclusively) five 242 minutes prior to the start of FACS analyses (Figure 1, FACS Aria II SORP, BD

243 Biosciences, San Jose, CA, USA). Once DAPI+ cells and other cell types (endothelial,

244 leukocytes, and hematopoietic) were excluded, the cells identified using FACS were

245 small and of round shape indicating a relatively low complexity. Cells stained for PE-

246 conjugated anti-alpha-7 integrin and APC-conjugated anti-CD34 were sorted out and

247 were named alpha-7 integrin+/CD34+ muscle progenitors (Figure 1). Muscle progenitor

248 cells were expressed as the percentage of alpha-7 integrin+/CD34+ progenitors to the

249 total numbers of isolated viable cells. These cells were specifically preserved following

250 the sorting experiments to be further analyzed as described below.

\section{Satellite cell RNA extraction}

252 Total RNA was first isolated from the yield of sorted satellite cells using Trizol reagent

253 following the manufacturer's protocol (Life technologies, Carlsbad, CA, USA). Total

254 RNA concentrations were determined spectrophotometrically using the NanoDrop 1000

255 (Thermo Scientific, Waltham, MA, USA).

256 Procedures of mRNA reverse transcription (RT)

257 A single RT was performed from which all the target genes of the study were analyzed.

258 First-stranded cDNA was generated from mRNA using oligo(dT) $)_{12-18}$ primers and the

259 Super-Script III reverse transcriptase following the manufacturer's instructions (Life

260 Technologies). 


\section{Quantitative real time-PCR amplification (qRT-PCR)}

262 TaqMan based qPCR reactions were performed using the ABI PRISM 7900HT

263 Sequence Detector System (Life Technologies, Carlsbad, CA, USA) together with 264 commercially available gene expression assays. The probes corresponding to the 265 following genes involved in muscle regeneration were tested: pax7 (Mn01354484_m1, 266 Life Technologies), myogenic differentiation 1 (myoD) (Mm00440387_m1, Life 267 Technologies), marker of cell proliferation ki-67 (ki67) (Mm01278617_m1, Life 268 Technologies) and myogenin (Mm00446194_m1, Life Technologies). The 269 housekeeping gene glyceraldehyde-3-phosphate dehydrogenase (gapdh)

270 (Mm99999915_g1, Life Technologies) served as the endogenous control for mRNA 271 gene expression. Reactions were run in duplicates, and mRNA data were collected and 272 subsequently analyzed using the sequence detection system relative quantification 273 software version 2.4 (Applied BioSystems), in which the comparative $\mathrm{C}_{\mathrm{T}}$ method (2$27 \Delta^{\Delta \Delta C T}$ ) for relative quantification was employed (Livak and Schmittgen, 2001).

275 Satellite cell identification using immunofluorescence microscopy

276 The protocol used in these experiments was similar to that published in previous studies 277 (Arentson-Lantz et al, 2016;Snijders et al, 2014;Suetta et al, 2013). Gastrocnemius and 278 soleus muscles were fixed in $4 \%$ paraformaldehyde solution, pH 6.9 (EMD Millipore 279 corporation, Billerica, MA, USA) and were embedded progressively with increasing 280 concentrations of sucrose. They were subsequently embedded in tissue-tek optimal 281 cutting temperature (OCT) compound (Sakura Finetek, Torrance, CA, USA) to be snap282 frozen in 2-methyl-butane immersed in liquid nitrogen as previously described (Barthel 283 and Raymond, 1990). Ten- $\mu \mathrm{m}$ frozen sections were cut using a cryostat-microtome 284 (Leica CM3050S, Leica Biosystems, Wetzlar, Germany) at $-20^{\circ} \mathrm{C}$ and were mounted on 285 glass slides. Immunofluorescence staining was used to detect satellite cells in both 
286 quiescent and proliferative states using specific antibodies (see below). Briefly, muscle

287 cross-sections were air-dried for 30 minutes and were rinsed with PBS for another 15

288 minutes. PBS was used to rinse the sections among the different incubation steps. After

289 rinsing, the sections were put in cold methanol for six more minutes. Then, the sections

290 were boiled using a hot bath in $0.1 \mathrm{M}$ citrate buffer ( $\mathrm{pH}$ 6.0) for 12 minutes, and were

291 then blocked with $10 \%$ goat serum in PBS for two hours. Subsequently, sections were

292 incubated with Mouse IgG blocking reagent (MOM) (Vector Laboratories, Burlingame,

293 CA, USA) for 30 minutes. Afterwards, they were incubated overnight with a mixture of

294 two antibodies: mouse monoclonal anti-pax7 antibody $(1: 20$; sc-81648, Santa Cruz

295 Biotechnology Inc., Dallas, TX, USA) and rabbit polyclonal anti-ki-67 antibody (1:100;

296 ab15580, Abcam, Cambridge, UK), prepared in an antibody solution (1\% goat serum

297 dissolved in PBS, at $4^{\circ} \mathrm{C}$ ). Anti-pax7 antibody was used to detect satellite cells, while

298 anti-ki-67 antibody was used to detect proliferating cells (namely blood cells and

299 proliferating myoblasts) (Arentson-Lantz et al, 2016;Snijders et al, 2014;Suetta et al,

300 2013). The double staining of cells with both anti-pax7 and anti-ki-67 simultaneously,

301 detected proliferating satellite cells. Following incubation with the primary antibodies

302 and after rinsing with PBS, the sections were incubated at room temperature with the

303 corresponding secondary antibodies for one hour: anti-mouse IgG1 Alexa Fluor 488

304 antibody and anti-rabbit IgG (H+L) Alexa Fluor Plus 555 (1:400 both, Invitrogen,

305 Thermo Fisher Scientific), also prepared in an antibody solution. Finally, the sections

306 were mounted using the fluorescent mounting medium DAPI G-Fluoromount medium

307 (Southern Biotech, Birmingham, AL, USA), which specifically stained DNA (allowing

308 identification of all nuclei) in the muscle sections. A fluorescence microscope $(\times 40$

309 objective, Nikon Eclipse Ni, Nikon, Tokyo, Japan) coupled with a digitizing camera

310 was used to identify and count the number of the satellite cells (10 fields) in each study

John Wiley \& Sons, Inc. 
311 sample. In each muscle section from gastrocnemius and soleus of the two study groups

312 of mice, results were expressed as the percentage of either pax7-positive, ki-67-positive,

313 or both pax7- and ki-67 double-stained nuclei to the total number of counted myonuclei

314 in the 10 fields.

315 Identification of satellite cells and regeneration events using electron microscopy

316 For these specific experiments only the gastrocnemius (larger size) could be used.

317 Gastrocnemius muscles were gently excised into very small fragments. These pieces

318 were then further cut into two 1 x $0.5 \mathrm{~mm}$-fragments on a smooth surface using

319 tweezers and a surgical blade. The muscle fragments were immediately immersed into a

320 fixative solution containing $2 \%$ glutaraldehyde in cacodylate buffer $(0.2 \mathrm{M}, \mathrm{pH} 7.4)$ for

32124 hours and were then post-fixed in $1 \%$ osmium tetroxide solution in the cacodylate

322 buffer for one more hour. The samples were subsequently dehydrated in a graded series

323 of ethanol from 70 to $100 \%$, were then transitioned into the intermediate solvent

324 propylene oxide, to be finally embedded with increasing concentrations of an Epon

325 resin (until 100\% of epon resin-embedding was reached). Subsequently, samples were

326 embedded longitudinally in a mold containing fresh resin, and were polymerized at

$32760^{\circ} \mathrm{C}$ for 24 hours. Semithin sections of $0.4 \mu \mathrm{m}$ each were then obtained using a glass

328 knife, and were immediately stained with toluidine blue in order to identify the specific

329 region to be thin-sectioned at 50-80 $\mathrm{nm}$ using a diamond knife (Diatome, Nidau,

330 Switzerland) and an ultramicrotome (Ultracut E, Reichert-Jung, Austria). The thin

331 sections were placed onto 250-mesh copper/nickel grids and were stained with uranyl

332 acetate and lead citrate. Satellite cells were identified and counted using a transmission

333 electron microscope (FEI CM100 TEM; Philips, Eindhoven, The Netherlands) with an

334 attached Veleta digital camera (iTEM, Olympus, Tokyo, Japan) and iTEM software was

335 used to capture the images (Davies, 1999). Satellite cells were identified as small round-

John Wiley \& Sons, Inc. 
336 shaped cells located between the basal lamina and the sarcolemma of the myofibers.

337 Fifty fields were counted in each study sample.

338 The following parameters were assessed in the ultrastructural muscle preparations from

339 the study muscle samples: 1) number of satellite cells, located between the basal lamina

340 and the sarcolemma, in the measured area $\left.\left(\mathrm{mm}^{2}\right), 2\right)$ early regeneration events

341 characterized by the presence of internal myonuclei located in groups in the measured

342 area $\left(\mathrm{mm}^{2}\right)$, and 3) late regeneration events identified as the presence of isolated internal

343 myonuclei in the measured area $\left(\mathrm{mm}^{2}\right)$. Numbers of all these three ultrastructural events

344 were counted in 50 fields of all the study samples and are illustrated in Table 2.

\section{Statistical analysis}

346 Results are presented as mean values (standard deviation). The normality of the study

347 variables was explored using the Shaphiro-Wilk test. Food intake and percentage of

348 change of both total body weight and limb strength variables are represented in Table 1,

349 whereas the biological variables are represented in Table 2 and Figures (mean and

350 standard deviation). The following statistical approaches were used in the study for

351 different purposes. Firstly, the variables food intake and percentage of change of total

352 body weight and limb strength variables in mice from the 7-day I cohort were compared

353 with mice from the 7-day R cohort using the unpaired Student's T-test. Secondly, one-

354 way analysis of variance (ANOVA) was used to assess potential differences in all the

355 study biological variables among the three study groups of muscles samples: 7-day I, 7-

356 day $\mathrm{R}$ and the control muscles from the contralateral hindlimb. Tukey post hoc analysis

357 was used to adjust for multiple comparisons. A level of significance of $p<0.05$ was

358 established in the study. Comparisons of biological variables of the muscles obtained

359 from the contralateral hindlimb showed no significant differences between the seven-

360 day I and the seven-day R groups of mice. Thus, for the sake of clarity and conciseness,

John Wiley \& Sons, Inc. 
361 this group has been named contralateral control muscles in the results below.

362

363 RESULTS

364 Physiological characteristics of the study animals

365 As shown in Table 1, food intake did not differ between the 7-day I and 7-day R mice.

366 The variables percentage of body weight and limb strength gain were significantly

367 increased in the 7-day R compared to 7-day I mice (Table 1).

368 Disuse reduces satellite cell numbers in muscles

369 The number of alpha-7 integrin+/CD34+ satellite cells of the 7-day I group was 370 significantly reduced compared to the contralateral control muscles (Figure 2). Alpha-7 371 integrin+/CD34+ satellite cell numbers were significantly higher in the 7-day $\mathrm{R}$ mice

372 compared to the 7-day I group, although they did not reach levels detected in the 373 contralateral control muscles (Figure 2). Immunofluorescence pax7-positive cells were 374 also significantly reduced in gastrocnemius and soleus muscles of the 7-day I animals 375 compared to the contralateral control muscles (Figures 3A-3D, respectively). Levels of 376 immunofluorescence pax7-positive cells were also lower in 7-day R muscles compared 377 to contralateral control muscles in both gastrocnemius and soleus muscles (Figures 3A$3783 \mathrm{D}$, respectively). In the gastrocnemius, but not the soleus, numbers of proliferating 379 nuclei (ki-67 positively stained) were significantly higher in the 7-day R mice compared 380 to both 7-day I and contralateral control muscles (Figures 3A-3D). Additionally, in the 381 gastrocnemius, but not the soleus, specific proliferating satellite cells (both pax7 and ki38267 double-stained) were significantly greater in the 7-day $\mathrm{R}$ group compared to 383 contralateral control muscles (Figures 3A-3D).

384 Ultrastructural analyses of satellite cells and muscle regeneration

385 Examples of the normal ultrastructure of muscle sections and of a satellite cell are 
shown in Figures 4A-4B, respectively. Compared to contralateral control muscles,

387 ultrastructural satellite cell counts were significantly greater in the gastrocnemius of the

388 7-day R mice, whereas no significant differences were seen in the muscles of the 7-day

389 I animals (Table 2). Numbers of grouped internal nuclei (early regeneration phase) were

390 significantly greater in the 7-day I and 7-day R mice compared to the contralateral

391 control muscles (Table 2 and Figure 4C). Compared to contralateral control muscles, in

392 the gastrocnemius, counts of isolated nuclei (marker of late regeneration phase) were

393 significantly lower in the 7-day I mice, while they were significantly greater in the 7-

394 day R animals (Table 2 and Figure 4D). Satellite cell fusion to existing myofibers was

395 demonstrated in the gastrocnemius ultrastructural sections of the 7-day I mice (Figures

396 5A-C) and the 7-day R animals (Figure 5D). Sarcomeric membrane folding took place

397 following satellite cell internalization (Figure 5B).

398 Disuse induces a specific pattern of regenerative markers in muscles

399 Levels of ki67 gene expression were significantly higher in the 7-day R group compared 400 to both 7-day I mice and the contralateral control muscles (Figure 6). Pax7 and MyoD 401 gene expression levels were significantly higher in the 7-day I mice compared to the 402 contralateral control muscles, while the expression of these markers was significantly 403 lower in hindlimb muscles from 7-day R animals compared to 7-day I mice (Figures 404 7A-7B, respectively). Myogenin expression did not significantly differ between the 7405 day I and the contralateral control muscles, whereas a significant rise in this marker was 406 observed in muscles of the 7-day R animals compared to both the 7-day I mice and the 407 contralateral control muscles (Figure 7C).

408

409 DISCUSSION

410 In the study, a large-scale approach, in which satellite cells were isolated from all the 
411 limb muscles using FACS, was followed. The rationale to use such methodologies was

412 to identify a pure population of muscle progenitors as demonstrated in previous studies

413 (Yin et al, 2013). In fact, one of the main goals in the study was to characterize the gene

414 expression profile of the isolated progenitor cells during recovery following a period of

415 hindlimb muscle disuse for seven days, which was defined as a key time-point to

416 analyze early and late events as previously shown in this experimental model (Chacon-

417 Cabrera et al, 2016; Chacon-Cabrera et al, 2017a). Furthermore, the use of

418 methodologies such as histological procedures enabled us to define the localization and

419 numbers of active and proliferating satellite cells in the study muscles. Besides, electron

420 microscopy analyses also revealed that differential events of early and late regeneration

421 phases took place in the muscles of the two study groups of mice.

422 In the current investigation, the study hypothesis has been confirmed to a great

423 extent. A specific program of muscle regeneration was induced during recovery

424 following hindlimb immobilization. The number of progenitor muscle cells was reduced

425 in limb muscles isolated from mice exposed to a seven-day period of hindlimb disuse.

426 Histological analyses also revealed that pax7-positive satellite cells were reduced in 427 both slow- and fast-twitch muscle types of the 7-day I mice. Additionally, 428 ultrastructural events of late muscle regeneration also decreased in the gastrocnemius of 429 the latter animals. In fact, these findings are consistent with what has been found in 430 other models of disuse, in which a significant decline in muscle satellite counts was 431 demonstrated along with severe atrophy in young healthy subjects at rest (Arentson432 Lantz et al, 2016;Mackey et al, 2009) and in experimental models of disuse muscle 433 atrophy (Darr and Schultz, 1989; Mitchell and Pavlath, 2004;Wang et al, 2007). In 434 elderly subjects, a decline in muscle satellite cells was also observed following 435 immobilization for two weeks using a whole-leg casting (Suetta et al, 2013). Another 
436 study, however, revealed no significant changes in muscle satellite cell counts in the

437 quadriceps muscle of healthy young individuals exposed to several weeks of one-legged 438 knee immobilization using a cast (Snijders et al, 2014). Discrepancies among studies 439 could be attributed to differences in the experimental models, age of the study subjects, 440 previous activity of the target individuals, and/or methodologies used to identify the 441 satellite cell numbers. A major strength and novelty in the current study was the use of 442 three different approaches to identify satellite cells and muscle regeneration features in 443 the mice exposed to unloading and reloading.

444 Importantly, removal of the splint (recovery period) induced a rise in the number 445 of progenitor cells in the limb muscles of the mice during recovery. Although in these 446 mice the content of satellite cells did not reach the baseline levels observed in the 447 contralateral control muscles, it was significantly greater than in the seven-day I 448 animals. These results imply that proliferation of muscle progenitors is a key step in the 449 initiation of the muscle regeneration process during the recovery period. In line with 450 this, numbers of proliferating satellite cells and ultrastructural cell counts were greater 451 in the gastrocnemius of the seven-day R mice compared to control muscles as well as 452 ultrastructural events of late muscle regeneration (isolated internal nuclei). In the soleus 453 muscle, however, no differences were seen among the study groups probably due to the 454 different fiber type composition of this muscle. These findings suggest that the fast455 twitch gastrocnemius may have contributed to a great extent to the increased numbers of 456 progenitor cells detected in the seven-day R muscles during the FACS analyses. 457 Importantly, in the animals, reestablishment of normal muscle activity following a 458 resting period may mimic what happens in response to exercise training in humans. As 459 such, strength training was also shown to induce a significant increase in satellite cell 460 numbers along with the expression of myogenic regulatory and growth factors in the 
461 quadriceps muscle of healthy young subjects (Hanssen et al, 2013).

462 Levels of proliferating cells in general as measured by the ki-67 marker were

463 only significantly increased in muscle progenitor cells in the animals exposed to seven-

464 day recovery compared to levels detected in the control muscles and the seven-day

465 immobilized mice. As abovementioned, numbers of proliferating satellite cells

466 identified as those positively stained for both pax7 and ki-67 antigens were also greater

467 in the gastrocnemius of seven-day $\mathrm{R}$ mice. These findings are in line with those

468 previously reported in which counts of active satellite cell as identified exclusively by

469 ki-67 expression levels also increased following muscle activity in healthy humans

470 (Mackey et al, 2009). Interestingly, the rise in ki-67 expression also corresponded to

471 that seen in the muscle progenitor cells during recovery. It should be mentioned that in

472 the current study, proliferating satellite cells were detected using two antibodies since

473 other cell types (e.g. hematopoietic cells) might have also proliferated during the

474 recovery phase in the study muscles. We considered this to be a more accurate approach

475 than that exclusively based on ki-67 staining.

476 Characterization of the muscle progenitors from a molecular standpoint has

477 revealed that the expression of markers such as a $\operatorname{pax} 7$ and myoD was upregulated in the

478 muscle progenitors of mice during unloading, while it reached baseline levels during

479 reloading. These findings suggest that despite the decrease in muscle progenitors

480 observed during unloading, satellite cells were not in $\mathrm{G}_{0}$ phase as myoD is expressed in

481 myogenic precursor cells but not in quiescent satellite cells (Yin et al, 2013). The

482 current observations are in line with those reported in models of disuse muscle atrophy,

483 in which the expression of markers of satellite cell activation was upregulated, while

484 satellite cell counts were also reduced (Arentson-Lantz et al, 2016;Snijders et al,

485 2014; Suetta et al, 2013).

John Wiley \& Sons, Inc. 
The process of satellite cell activation during skeletal muscle injury including

487 unloading is rather complex. For instance, periods of satellite cell proliferation and

488 fusion to the existing fiber syncytium were demonstrated in the gastrocnemius of mice 489 exposed to hindlimb suspension (Ferreira et al, 2006). In the present investigation, 490 fusion of satellite cells was also observed in the gastrocnemius of muscles exposed to 491 immobilization for seven days (Figure 5). On this basis, it would be possible to 492 conclude that activation of satellite cells should have taken place early during 493 unloading, thus, leading to the fusion of those cells to the differentiated myofibers 494 immediately afterwards. These findings most likely account for the decrease in muscle 495 progenitors seen in the 7-day I mice as revealed by both the FACS (all hindlimb 496 muscles) and histological analyses (gastrocnemius). Furthermore, ultrastructural events 497 of early regeneration (grouped internal nuclei as a marker of myofiber fusion) were, 498 indeed, identified and increased in the mice exposed to seven-day I compared to control 499 muscles. Collectively, these observations are also consistent with the decrease in pax7 500 and myoD mRNA expression levels detected in the hindlimb muscles of animals during 501 recovery in the present study. Moreover, mRNA expression levels of myogenin were 502 upregulated in the latter muscles, which implied that during reloading, terminal 503 differentiation was underway following the required decline in the expression of 504 satellite cell activation markers (Yablonka-Reuveni and Rivera, 1994).

\section{Conclusions}

506 Recovery following hindlimb immobilization was characterized by a specific program 507 of muscle regeneration (cellular and molecular) events. Hindlimb immobilization 508 induced a decline in muscle progenitor cells together with an upregulation of markers of 509 satellite cell activation, suggesting that fusion to existing myofibers takes place during 510 unloading as demonstrated by the ultrastructural analyses. Muscle recovery as a result 
511 of splint removal induced a significant rise in muscle precursor cells and regeneration

512 events along with a reduction in the expression of satellite cell activation markers and a

513 concomitant rise in terminal muscle differentiation expression. These are novel, relevant

514 findings of potential applicability for the treatment of disuse muscle atrophy, which is

515 commonly associated with severe chronic and acute conditions.

516

John Wiley \& Sons, Inc. 
1

2

3

4

5

6

7

8

9

10

11

12

13

14

15

16

17

18

19

20

21

22

23

24

25

26

27

28

29

30

31

32

33

34

35

36

37

38

39

40

41

42

43

44

45

46

47

48

49

50

51

52

53

54

55

56

57

58

59

60

\section{ACKNOWLEDGEMENTS}

518 The authors are very grateful to the Cell Biology Group (Professor Pura Muñoz-

519 Cànoves) at Universitat Pompeu Fabra and the CRG/UPF FACS Unit both from

520 Barcelona Biomedical Research Park (PRBB), Barcelona (Spain) for their help with

521 satellite cell isolation procedures. The authors are also very thankful to Maria Mercedes

522 Simón-Grimaldos for her help with electron microscopy sampling and processing and to

523 Mukaddes Izci for her help with part of the immunofluorescence microscopy

524 experiments. Additionally, the authors are also thankful to Mr. Xavier Duran-Jordà for

525 his statistical advice and data analyses.

526 Authors' conflicts of interest in relation to the study: None to declare.

527 Editorial support: None to declare.

528

529

530

531

532

533

534

535

536

537

538

John Wiley \& Sons, Inc. 
Arentson-Lantz EJ, English KL, Paddon-Jones D, Fry CS (2016). Fourteen days of bed rest induces a decline in satellite cell content and robust atrophy of skeletal muscle fibers in middle-aged adults. J Appl Physiol (1985 ) 120:965-975.

544 Barreiro E (2017). Skeletal Muscle Dysfunction in COPD: Novelties in The Last 545 Decade. Arch Bronconeumol 53:43-44.

546 Barreiro E, Bustamante V, Cejudo P, Galdiz JB, Gea J, de LP, Martinez-Llorens 547 J, Ortega F, Puente-Maestu L, Roca J, Rodriguez-Gonzalez Moro JM (2015a). 548 Guidelines for the evaluation and treatment of muscle dysfunction in patients with 549 chronic obstructive pulmonary disease. Arch Bronconeumol 51:384-395.

550 Barreiro E, Gea $\mathbf{J}$ (2015). Epigenetics and muscle dysfunction in chronic 551 obstructive pulmonary disease. Transl Res 165:61-73.

552 Barreiro E, Gea J (2016). Molecular and biological pathways of skeletal muscle 553 dysfunction in chronic obstructive pulmonary disease. Chron Respir Dis 13:297554311.

555 Barreiro E, Puig-Vilanova E, Marin-Corral J, Chacon-Cabrera A, Salazar556 Degracia A, Mateu X, Puente-Maestu L, Garcia-Arumi E, Andreu AL, Molina L 557 (2016). Therapeutic Approaches in Mitochondrial Dysfunction, Proteolysis, and 558 Structural Alterations of Diaphragm and Gastrocnemius in Rats With Chronic 559 Heart Failure. J Cell Physiol 231:1495-1513.

560 Barreiro E, Sznajder JI (2013). Epigenetic regulation of muscle phenotype and 561 adaptation: a potential role in COPD muscle dysfunction. J Appl Physiol (1985 ) 562 114:1263-1272.

563 Barreiro E, Sznajder JI, Nader GA, Budinger GR (2015b). Muscle dysfunction in 564 patients with lung diseases: a growing epidemic. Am J Respir Crit Care Med 565 191:616-619.

566 Barthel LK, Raymond PA (1990). Improved method for obtaining 3-microns 567 cryosections for immunocytochemistry. J Histochem Cytochem 38:1383-1388.

568 Chacon-Cabrera A, Fermoselle C, Salmela I, Yelamos J, Barreiro E (2015). 569 MicroRNA expression and protein acetylation pattern in respiratory and limb 570 muscles of Parp-1(-/-) and Parp-2(-/-) mice with lung cancer cachexia. Biochim 571 Biophys Acta 1850:2530-2543.

572 Chacon-Cabrera A, Fermoselle C, Urtreger AJ, Mateu-Jimenez M, Diament MJ, 573 De Kier Joffe ED, Sandri M, Barreiro E (2014). Pharmacological strategies in lung 574 cancer-induced cachexia: effects on muscle proteolysis, autophagy, structure, and 575 weakness. J Cell Physiol 229:1660-1672.

576 Chacon-Cabrera A, Gea J, Barreiro E (2017a). Short- and Long-Term Hindlimb 577 Immobilization and Reloading: Profile of Epigenetic Events in Gastrocnemius. J 578 Cell Physiol 232:1415-1427. 
579 Chacon-Cabrera A, Lund-Palau H, Gea J, Barreiro E (2016). Time-Course of 580 Muscle Mass Loss, Damage, and Proteolysis in Gastrocnemius following Unloading 581 and Reloading: Implications in Chronic Diseases. PLoS One 11:e164951.

582 Chacon-Cabrera A, Mateu-Jimenez M, Langohr K, Fermoselle C, Garcia-Arumi 583 E, Andreu AL, Yelamos J, Barreiro E (2017b). Role of PARP activity in lung 584 cancer-induced cachexia: Effects on muscle oxidative stress, proteolysis, anabolic 585 markers, and phenotype. J Cell Physiol 232:3744-3761.

586 Darr KC, Schultz E (1989). Hindlimb suspension suppresses muscle growth and 587 satellite cell proliferation. J Appl Physiol (1985 ) 67:1827-1834.

588 Davies HA (1999). General preparation of material and staining of sections. 589 Methods Mol Biol 117:1-11.

590 Fearon K, Strasser F, Anker SD, Bosaeus I, Bruera E, Fainsinger RL, Jatoi A, 591 Loprinzi C, MacDonald N, Mantovani G, Davis M, Muscaritoli M, Ottery F, 592 Radbruch L, Ravasco P, Walsh D, Wilcock A, Kaasa S, Baracos VE (2011). 593 Definition and classification of cancer cachexia: an international consensus. Lancet 594 Oncol 12:489-495.

595 Fermoselle C, Rabinovich R, Ausin P, Puig-Vilanova E, Coronell C, Sanchez F, 596 Roca J, Gea J, Barreiro E (2012). Does oxidative stress modulate limb muscle 597 atrophy in severe COPD patients? Eur Respir J 40:851-862.

598 Ferreira R, Neuparth MJ, Ascensao A, Magalhaes J, Vitorino R, Duarte JA, 599 Amado F (2006). Skeletal muscle atrophy increases cell proliferation in mice 600 gastrocnemius during the first week of hindlimb suspension. Eur J Appl Physiol $601 \quad 97: 340-346$.

602 Hanssen KE, Kvamme NH, Nilsen TS, Ronnestad B, Ambjornsen IK, Norheim F, 603 Kadi F, Hallen J, Drevon CA, Raastad T (2013). The effect of strength training 604 volume on satellite cells, myogenic regulatory factors, and growth factors. Scand $\mathbf{J}$ 605 Med Sci Sports 23:728-739.

606 Livak KJ, Schmittgen TD (2001). Analysis of relative gene expression data using 607 real-time quantitative PCR and the 2(-Delta Delta C(T)) Method. Methods 25:402608408.

609 Mackey AL, Kjaer M, Charifi N, Henriksson J, Bojsen-Moller J, Holm L, Kadi F 610 (2009). Assessment of satellite cell number and activity status in human skeletal 611 muscle biopsies. Muscle Nerve 40:455-465.

612 Maltais F, Decramer M, Casaburi R, Barreiro E, Burelle Y, Debigare R, 613 Dekhuijzen PN, Franssen F, Gayan-Ramirez G, Gea J, Gosker HR, Gosselink R, 614 Hayot M, Hussain SN, Janssens W, Polkey MI, Roca J, Saey D, Schols AM, Spruit 615 MA, Steiner M, Taivassalo T, Troosters T, Vogiatzis I, Wagner PD (2014). An 616 official American Thoracic Society/European Respiratory Society statement: 617 update on limb muscle dysfunction in chronic obstructive pulmonary disease. Am 618 J Respir Crit Care Med 189:e15-e62.

619 Marquis K, Debigare R, Lacasse Y, LeBlanc P, Jobin J, Carrier G, Maltais F 
620 (2002). Midthigh muscle cross-sectional area is a better predictor of mortality than 621 body mass index in patients with chronic obstructive pulmonary disease. Am $\mathbf{J}$ 622 Respir Crit Care Med 166:809-813.

623 Mitchell PO, Pavlath GK (2004). Skeletal muscle atrophy leads to loss and 624 dysfunction of muscle precursor cells. Am J Physiol Cell Physiol 287:C1753625 C1762.

626 Pasut A, Oleynik P, Rudnicki MA (2012). Isolation of muscle stem cells by 627 fluorescence activated cell sorting cytometry. Methods Mol Biol 798:53-64.

628 Patel MS, Natanek SA, Stratakos G, Pascual S, Martinez-Llorens J, Disano L, 629 Terzis G, Hopkinson NS, Gea J, Vogiatzis I, Maltais F, Polkey MI (2014). Vastus 630 lateralis fiber shift is an independent predictor of mortality in chronic obstructive 631 pulmonary disease. Am J Respir Crit Care Med 190:350-352.

632 Puig-Vilanova E, Ausin P, Martinez-Llorens J, Gea J, Barreiro E (2014a). Do 633 epigenetic events take place in the vastus lateralis of patients with mild chronic 634 obstructive pulmonary disease? PLoS One 9:e102296.

635 Puig-Vilanova E, Martinez-Llorens J, Ausin P, Roca J, Gea J, Barreiro E (2015). 636 Quadriceps muscle weakness and atrophy are associated with a differential 637 epigenetic profile in advanced COPD. Clin Sci (Lond) 128:905-921.

638 Puig-Vilanova E, Rodriguez DA, Lloreta J, Ausin P, Pascual-Guardia S, Broquetas 639 J, Roca J, Gea J, Barreiro E (2014b). Oxidative stress, redox signaling pathways, 640 and autophagy in cachectic muscles of male patients with advanced COPD and 641 lung cancer. Free Radic Biol Med 79C:91-108.

642 Seymour JM, Spruit MA, Hopkinson NS, Natanek SA, Man WD, Jackson A, 643 Gosker HR, Schols AM, Moxham J, Polkey MI, Wouters EF (2010). The 644 prevalence of quadriceps weakness in COPD and the relationship with disease 645 severity. Eur Respir J 36:81-88.

646 Snijders T, Wall BT, Dirks ML, Senden JM, Hartgens F, Dolmans J, Losen M, 647 Verdijk LB, van Loon LJ (2014). Muscle disuse atrophy is not accompanied by 648 changes in skeletal muscle satellite cell content. Clin Sci (Lond) 126:557-566.

649 Suetta C, Frandsen U, Mackey AL, Jensen L, Hvid LG, Bayer ML, Petersson SJ, 650 Schroder HD, Andersen JL, Aagaard P, Schjerling P, Kjaer M (2013). Ageing is 651 associated with diminished muscle re-growth and myogenic precursor cell 652 expansion early after immobility-induced atrophy in human skeletal muscle. J 653 Physiol 591:3789-3804.

654 Swallow EB, Reyes D, Hopkinson NS, Man WD, Porcher R, Cetti EJ, Moore AJ, 655 Moxham J, Polkey MI (2007). Quadriceps strength predicts mortality in patients 656 with moderate to severe chronic obstructive pulmonary disease. Thorax 62:115$657 \mathbf{1 2 0}$.

658 Vogelmeier CF, Criner GJ, Martinez FJ, Anzueto A, Barnes PJ, Bourbeau J, Celli 659 BR, Chen R, Decramer M, Fabbri LM, Frith P, Halpin DM, Lopez Varela MV, 660 Nishimura M, Roche N, Rodriguez-Roisin R, Sin DD, Singh D, Stockley R, Vestbo 
661 J, Wedzicha JA, Agusti A (2017). Global Strategy for the Diagnosis, Management, 662 and Prevention of Chronic Obstructive Lung Disease 2017 Report: GOLD 663 Executive Summary. Arch Bronconeumol 53:128-149.

664 Wang H, Hertlein E, Bakkar N, Sun H, Acharyya S, Wang J, Carathers M, 665 Davuluri R, Guttridge DC (2007). NF-kappaB regulation of YY1 inhibits skeletal 666 myogenesis through transcriptional silencing of myofibrillar genes. Mol Cell Biol 667 27:4374-4387.

668 Yablonka-Reuveni Z, Rivera AJ (1994). Temporal expression of regulatory and 669 structural muscle proteins during myogenesis of satellite cells on isolated adult rat 670 fibers. Dev Biol 164:588-603.

671 Yin H, Price F, Rudnicki MA (2013). Satellite cells and the muscle stem cell niche. 672 Physiol Rev 93:23-67.

673

674

675 


\section{FIGURE LEGENDS}

677 Figure 1: Representative flow-chart of the satellite cell isolation procedures using 678 FACS analyses. The different steps are represented in the different boxes. The flow of 679 the protocol is represented by dark thick arrows. Exclusion of the unwanted cells is 680 represented by the corresponding grey thin arrows. Definition of abbreviations: FACS, 681 fluorescence-activated cell sorting; DAPI, 4',6-diamino-2-fenilindol; Lin(-), negative 682 lineage.

683 Figure 2: Mean values and standard deviation of the percentage of alpha-7 684 integrin $+/ \mathrm{CD} 34+$ satellite cells in the contralateral control muscles ( $\mathrm{N}=10 /$ group), and 685 both the 7-day I ( $N=10 /$ group) and 7-day $\mathrm{R}(\mathrm{N}=10$ /group) cohorts of mice. Definition of 686 abbreviations: I, immobilization; R, recovery. Statistical significance is represented as 687 follows: *, p $<0.05$ and $* * *, p<0.001$ between hindlimb muscles from either 7 -day I or 688 7-day R mice and the contralateral control muscles; ${ }^{*}, \mathrm{p}<0.05$ between muscles from the 689 7-day I and 7-day R groups of animals.

690 Figure 3: Mean values and standard deviation of satellite cell counts as identified by 691 the number of pax7-positive cells ( $\mathrm{N}=8$ /group), ki-67-positive cells ( $\mathrm{N}=8 /$ group), and 692 pax7+ki-67-positive cells ( $N=8$ /group) in (A) gastrocnemius and (B) soleus muscles of 693 the contralateral control muscles (open bars), the 7-day I (black bars), and 7-day R (grey 694 bars) cohorts of mice. Representative images of immunofluorescence staining of DAPI 695 (left panels), pax7 (middle-left panels), ki-67 (middle-right panels) and cells positively 696 stained for both pax7 and ki-67 markers (right panels) in (C) gastrocnemius and (D) 697 soleus muscles of the contralateral control muscles, the 7-day I and the 7-day R cohorts 698 of mice. Thin arrows indicate pax7 positive cells, notched arrows indicate ki-67 positive 699 cells and triangle arrows indicate double-stained nuclei for both pax7 and ki-67 positive 700 cells (proliferating satellite cells). Definition of abbreviations: I, immobilization; R, 
recovery. Statistical significance is represented as follows: $*, p<0.05$ and ${ }^{* *}, \mathrm{p}<0.01$

702 between hindlimb muscles from either the 7-day I or the 7-day $\mathrm{R}$ animals and the 703 contralateral control muscles, ${ }^{\# \#}, \mathrm{p}<0.01$ between muscles of the the 7-day I and 7-day R 704 mouse groups.

705 Figure 4: Representative image of (A) a normal myofiber with two peripheral 706 myonuclei (thick black arrows) in gastrocnemius muscle obtained from a 7-day $\mathrm{R}$ 707 mouse, (B) a normal satellite cell in gastrocnemius from contralateral control muscles 708 (thick black arrows) located between the basal lamina (dashed arrow) and the 709 sarcolemma, (C) muscle in early regeneration phase in the gastrocnemius of a 7-day I 710 mouse characterized by the presence of grouped internal myonuclei (thick black arrow),

711 and (D) muscle in late regeneration phase in gastrocnemius muscle of a 7-day R mouse

712 characterized by the presence of an isolated internal myonucleus (thick black arrow).

713 Figure 5: Representative images of satellite cell fusion showing grouped internal 714 myonuclei (thick black arrows), indicative of recent fusion of satellite cells to existing 715 myofibers following proliferation in the gastrocnemius obtained from (A-C) 7-day I 716 mice and (D) 7-day R mice. Image shown in B corresponds to the enlargement of the 717 circled region marked in A micrograph, in which sarcomeric membrane folding took 718 place following satellite cell internalization.

719 Figure 6: Mean values and standard deviation of gene expression of ki67 (cell 720 proliferation marker) in the contralateral control muscles ( $\mathrm{N}=10$ /group) and in muscles 721 from the 7-day I (N=10/group) and 7-day $\mathrm{R}(\mathrm{N}=10 /$ group) mouse cohorts. Definition of 722 abbreviations: I, immobilization; R, recovery. Statistical significance is represented as 723 follows: **, $\mathrm{p}<0.01$ between hindlimb muscles from the 7 -day $\mathrm{R}$ and the contralateral 724 control muscles; ${ }^{\#}, \mathrm{p}<0.01$ between muscles from the 7-day I and the 7-day R groups of 725 mice. 
726 Figure 7: Mean values and standard deviation of gene expression of the markers (A) 727 pax7, (B) myoD and (C) myogenin in the contralateral control muscles ( $\mathrm{N}=10 /$ group) 728 and in hindlimb muscles from the 7-day I ( $N=10$ /group) and 7-day $R$ ( $N=10 /$ group) 729 mouse cohorts. Definition of abbreviations: I, immobilization; R, recovery. Statistical 730 significance is represented as follows: *, $\mathrm{p}<0.05$ between hindlimb muscles from either 731 the 7-day I or the 7-day R groups of mice and the contralateral control muscles; \#, $732 \mathrm{p}<0.05$ and ${ }^{\#}, \mathrm{p}<0.01$ between muscles from the 7-day I and the 7-day $\mathrm{R}$ groups of 733 mice.

734

735

John Wiley \& Sons, Inc. 
Table 1. Characteristics of the study animals

\begin{tabular}{|l|c|c|}
\hline & 7-day I mice, $\mathbf{n = 2 0}$ & 7-day R mice, $\mathbf{n = 2 0}$ \\
\hline Food intake (grams/24h) & $+4.7(0.6)$ & $+4.8(0.4)$ n.s. \\
\hline Total body weight, \% gain & $-3.7(4.5)$ & $+3.0(4.7)^{* * *}$ \\
\hline Limb strength gain, \% gain & $-12.9(7.6)$ & $+16.2(13.5)^{* *}$ \\
\hline
\end{tabular}

Data are presented as mean values (standard deviation).

Total body weight and limb strength gain variables were calculated in each animal group as described in Methods. Comparisons were made between the two groups of mice for each study variable (see statistical analyses in Methods section).

Definition of abbreviations: I, immobilization; R, recovery. Statistical significance is represented as follows: n.s., non-significant, **, $\mathrm{p}<0.01$, and $* * *, \mathrm{p}<0.001$ between 7 -day I and 7-day $\mathrm{R}$ mice. 
Table 2. Ultrastructural satellite cell identification and counts in the gastrocnemius of all study groups of mice

\begin{tabular}{|c|c|c|c|}
\hline & $\begin{array}{c}\text { Contralateral } \\
\text { control muscles } \\
(n=8)\end{array}$ & $\begin{array}{c}7 \text {-day I mice } \\
\quad(n=8)\end{array}$ & $\begin{array}{c}\text { 7-day } R \text { mice } \\
(n=8)\end{array}$ \\
\hline $\begin{array}{l}\text { SC counts } \\
\left(\mathrm{SC} / \mathrm{mm}^{2}\right)\end{array}$ & $13.1(6.3)$ & $18.2(6.9)$ & $22.4(6.4) * *$ \\
\hline $\begin{array}{l}\text { Muscle in early } \\
\text { regeneration phase } \\
\text { (grouped internal } \\
\text { myonuclei } / \mathrm{mm}^{2} \text { ) }\end{array}$ & $3.6(2.9)$ & $7.7(3.3)^{*}$ & $7.6(5.4)^{*}$ \\
\hline $\begin{array}{c}\text { Muscle in late } \\
\text { regeneration phase } \\
\text { (isolated internal } \\
\text { myonuclei } / \mathrm{mm}^{2} \text { ) }\end{array}$ & $10.7(3.2)$ & $5.9(2.7)^{*}$ & $16.7(4.4) * * \# \#$ \\
\hline
\end{tabular}

Data are presented as mean values (standard deviation).

Definition of abbreviations: I, immobilization; R, recovery; SC, satellite cells. Statistical significance is represented as follows: n.s., non-significant, *, $\mathrm{p}<0.05$ and $* * \mathrm{p}<0.01$ between either 7-day I or 7-day $\mathrm{R}$ mice, respectively, and the contralateral control muscles;, $\mathrm{p}<0.001$ between 7-day I and 7-day $\mathrm{R}$ animals. See Methods for detailed information on the quantification procedures of the study parameters. 
Figure 1

$254 \times 190 \mathrm{~mm}(300 \times 300$ DPI) 
Guitart et al. Figure 2

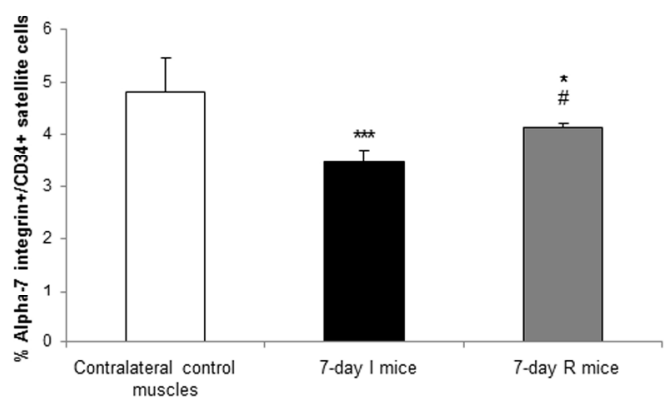

Figure 2

$254 \times 190 \mathrm{~mm}(300 \times 300$ DPI $)$

John Wiley \& Sons, Inc. 


1
2
3
4
5
6
7
8
9
10
11
12
13
14
15
16
17
18
19
20
21
22
23
24
25
26
27
28
29
30
31
32
33
34
35
36
37
38
39
40
41
42
43
40
45
49
50
51
52
53
55
50

Guitart et al. Figure 3

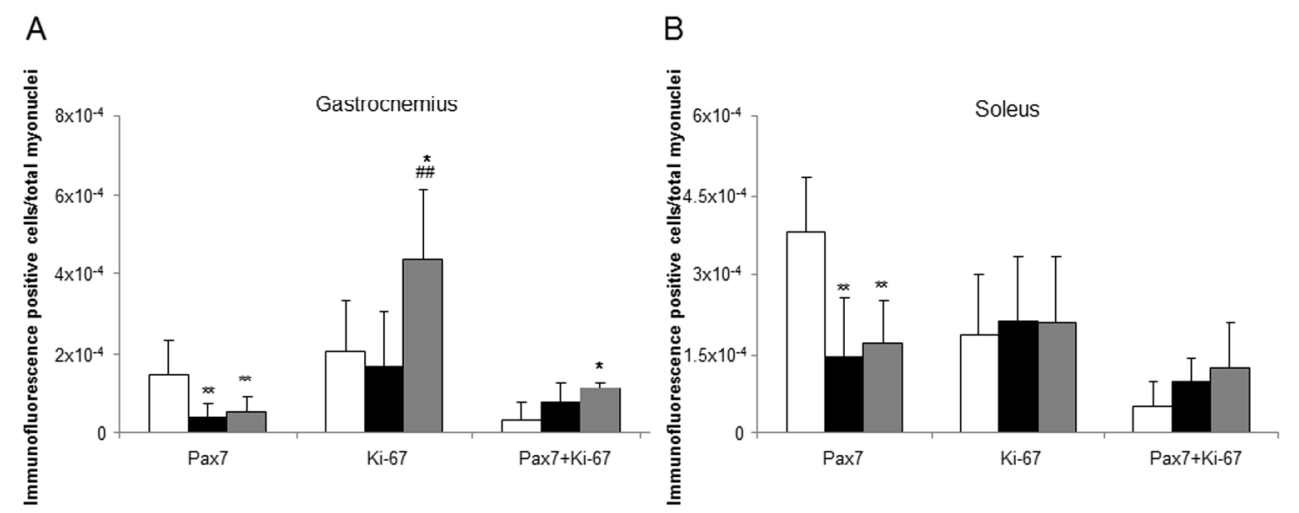

Figure $3 \mathrm{~A}-\mathrm{B}$

$254 \times 190 \mathrm{~mm}(300 \times 300$ DPI)

John Wiley \& Sons, Inc. 


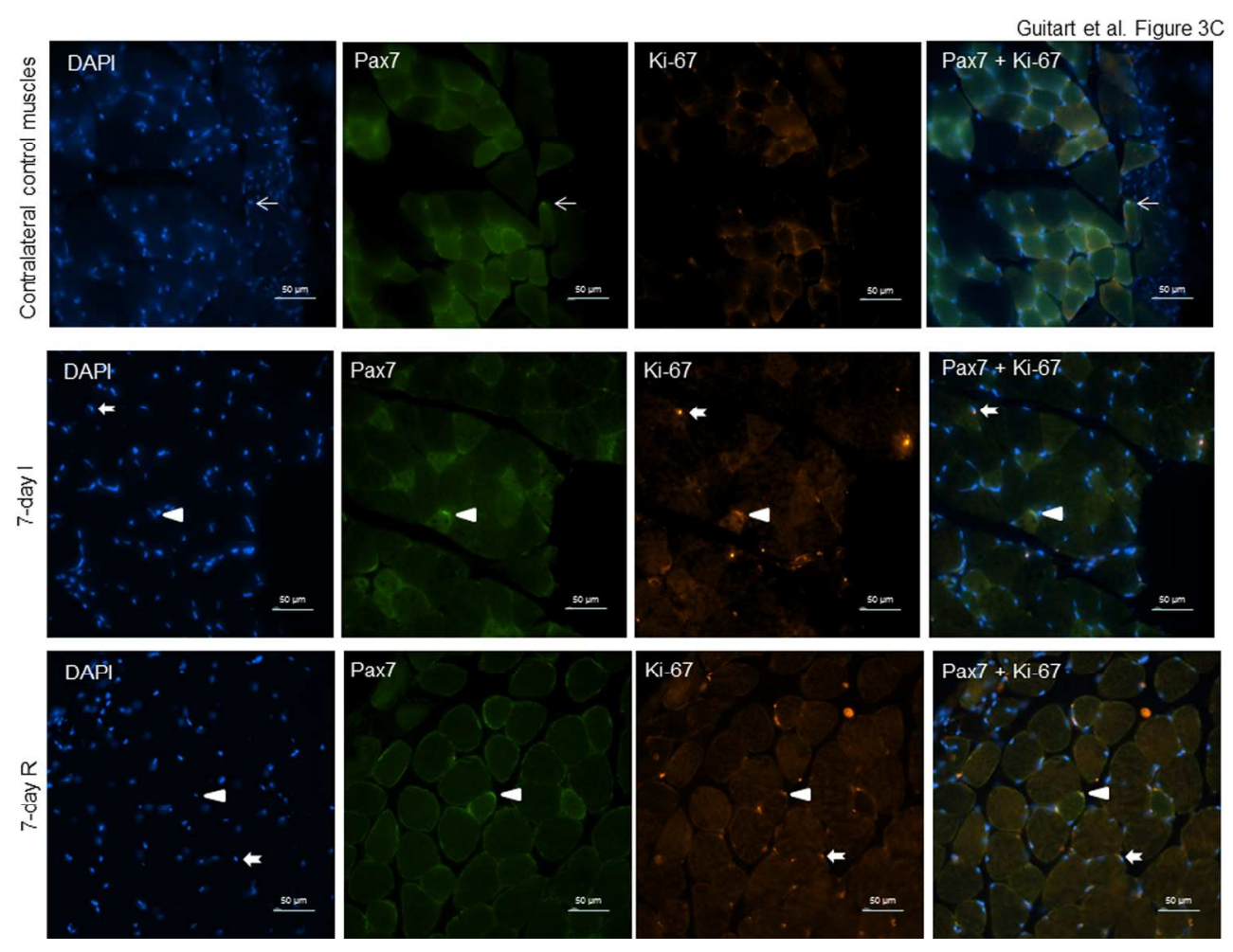

Figure 3C

$254 \times 190 \mathrm{~mm}(300 \times 300 \mathrm{DPI})$

John Wiley \& Sons, Inc. 


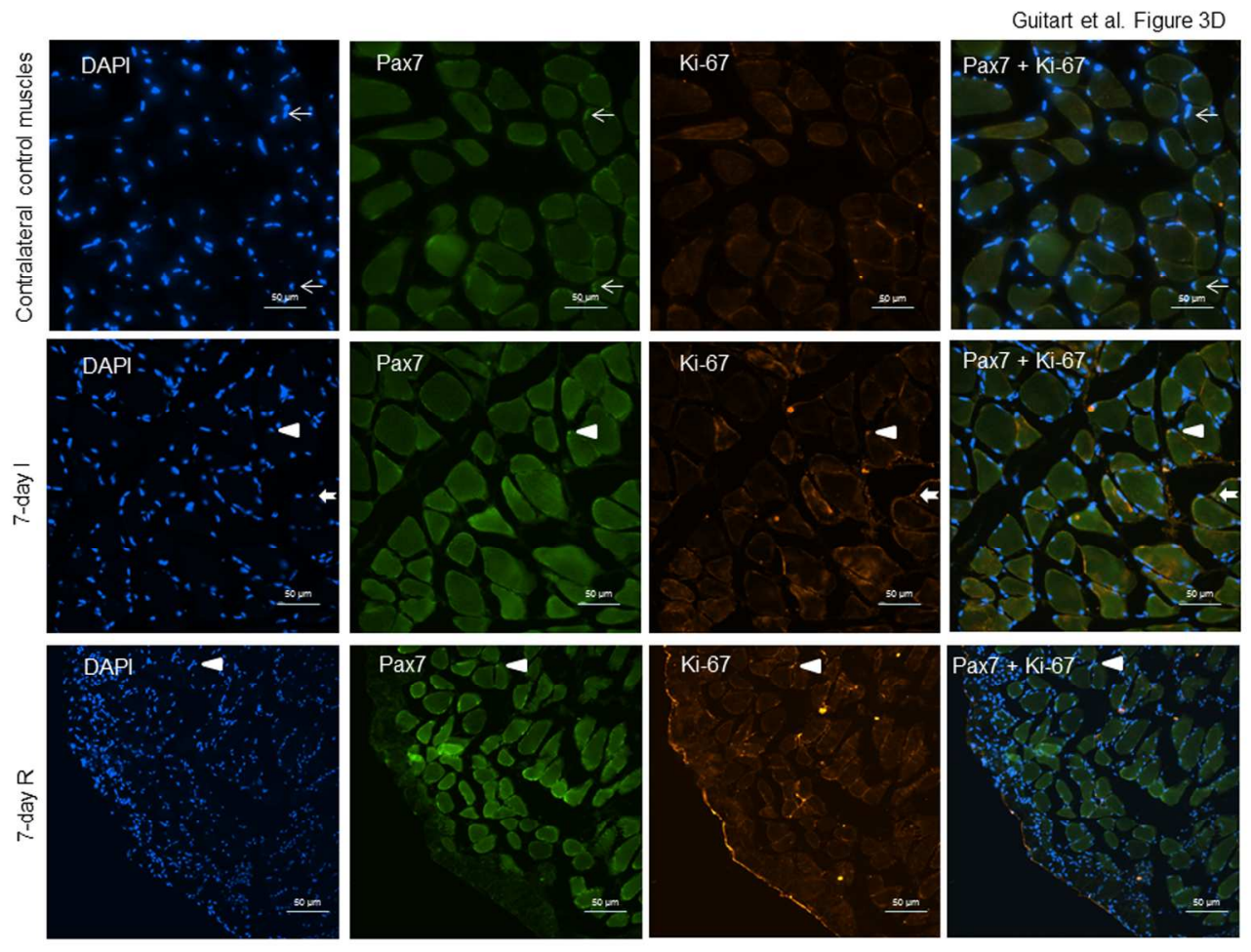

Figure 3D

$254 \times 190 \mathrm{~mm}(300 \times 300$ DPI $)$

John Wiley \& Sons, Inc. 


$$
\text { A }
$$

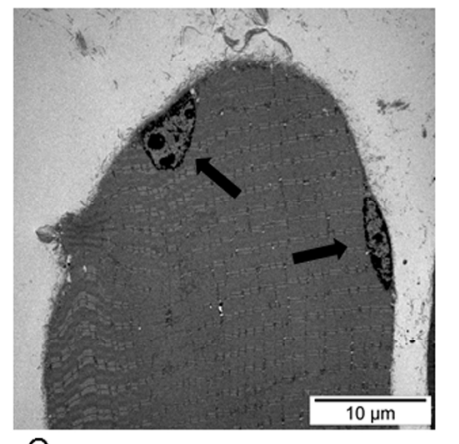
C

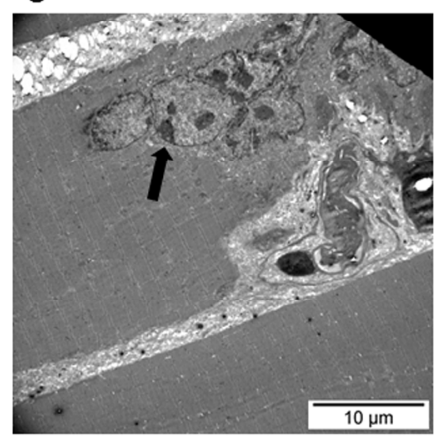

B
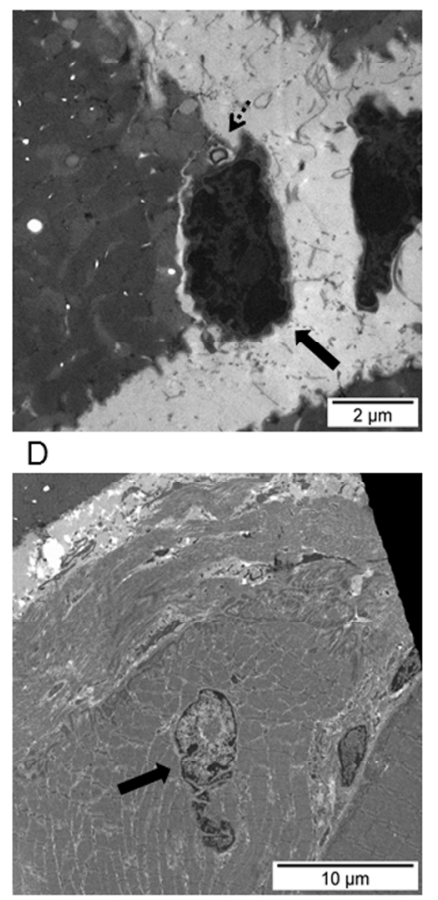

Figure 4

$254 \times 190 \mathrm{~mm}(300 \times 300 \mathrm{DPI})$

John Wiley \& Sons, Inc. 
Guitart et al. Figure 5

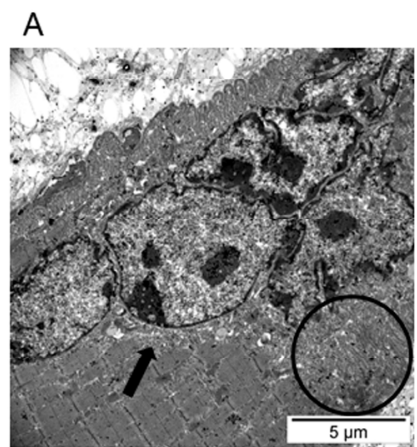

B

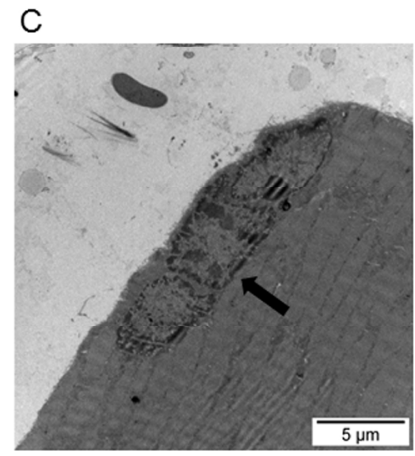

D
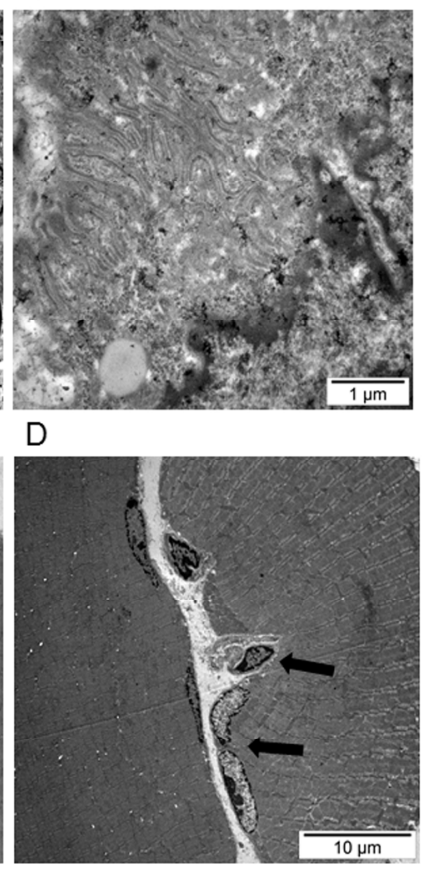

Figure 5

$254 \times 190 \mathrm{~mm}(300 \times 300 \mathrm{DPI})$

John Wiley \& Sons, Inc. 
Guitart et al. Figure 6

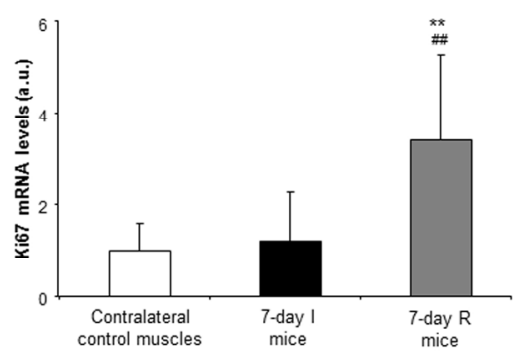

Figure 6

$254 \times 190 \mathrm{~mm}(300 \times 300$ DPI)

John Wiley \& Sons, Inc. 
1

2

3

4

5

6

7

8

9

10

11

12

13

14

15

16

17

18

19

20

21

22

23

24

25

26

27

28

29

30

31

32

33

34

35

36

37

38

39

40

41

42

43

44

45

46

47

48

49

50

51

52

53

54

55

56

57

58

59

60

\begin{abstract}
Guitart et al. Figure 7
\end{abstract}
A

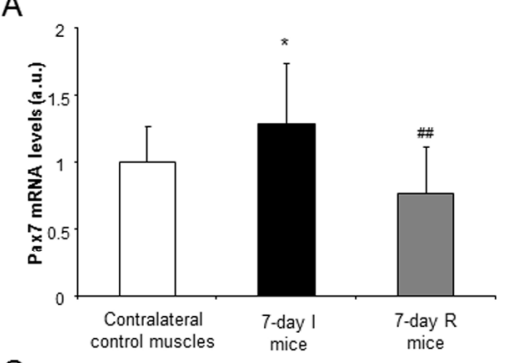

C

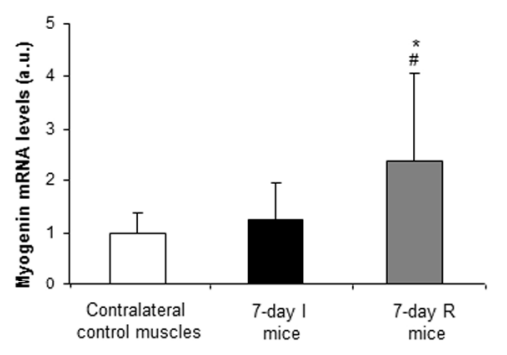

B

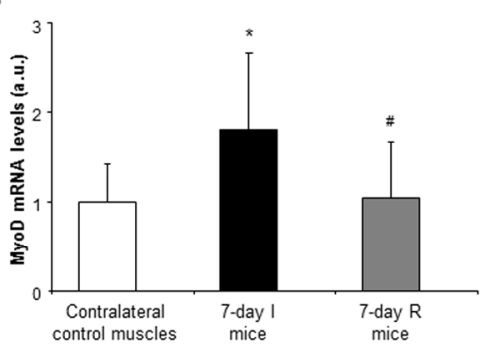

Figure 7

$254 \times 190 \mathrm{~mm}(300 \times 300 \mathrm{DPI})$

John Wiley \& Sons, Inc. 